\title{
Effects of tracheostomy in two cases of hypersomnia with periodic breathing
}

\author{
ELIO LUGARESI, ${ }^{1}$ GIORGIO COCCAGNA, MAGDA MANTOVANI, \\ AND FABRIZIO BRIGNANI
}

\author{
From the Clinica delle Malattie Nervose e Mentali dell'Università and Servizio di Fisiopatologia \\ Respiratoria del Policlinico S. Orsola, Bologna, Italy
}

SUMMARY Two non-obese patients suffering from hypersomnia with periodic breathing, who presented predominantly obstructive apnoea persisting throughout sleep, underwent tracheotomy with placement of a permanent tracheal cannula. Before tracheostomy there was a serious state of alveolar hypoventilation with a marked rise in pulmonary arterial pressure which appeared during sleep. After tracheostomy breathing during sleep became regular, pulmonary arterial pressure became normal, and daytime drowsiness disappeared. These observations suggest that the obstruction of the upper air tracts during sleep represents the most important factor in the pathogenesis of hypersomnia with periodic breathing.

The syndromes of respiratory insufficiency arising in the absence of pulmonary lesions have been grouped under the term 'general alveolar hypoventilation' by Fishman, Goldring, and Turino (1966). The most widely known among these are the Pickwickian syndrome and primary or central alveolar hypoventilation.

The Pickwickian syndrome (PS) (Auchincloss, 1955; Sieker, Estes, Kelser, and McIntosh, 1955; Burwell, Robin, Whaley, and Bickelmann, 1956) consists of extreme obesity, drowsiness, muscular jerks becoming more accentuated in the course of sleep, cyanosis, periodic respiration, secondary polycythaemia, cardiac hypertrophy, and right heart failure (Burwell et al., 1956).

According to several investigators obesity is of primary importance in the development of the syndrome since, by increasing the work of breathing, it produces a chronic alveolar hypoventilation (Auchincloss et al., 1955; Burwell et al., 1956; Carroll, 1956; Lillington, Anderson, and Brandenburg, 1957). On the other hand, it has been suggested that besides the obesity there must be a hypoexcitability of the respiratory centre (Sieker, Heyman, and Birchfield, 1960).

\footnotetext{
1 Reprint requests: Elio Lugaresi, Clinica delle Malattie Nervose e iMentali, Via Ugo Foscolo 7, Bologna, Italy.
}

All the other symptoms, including somnolence, have been considered secondary to the respiratory insufficiency.

Primary alveolar hypoventilation (PAH) (Rodman and Close, 1959) or Ondine's curse (Severinghaus and Mitchell, 1962) is a syndrome of alveolar hypoventilation clinically similar to the Pickwickian syndrome except that obesity is absent (Lugaresi, Coccagna, Petrella, Ceroni, and Mantovani, 1968a). This syndrome is attributed to hypoexcitability of the respiratory centre, since there are no lesions of the lungs or of the neuromuscular apparatus of breathing. In only a few cases (Naeye, 1961; Seriff, 1965) were anatomical lesions in the respiratory centre assumed or demonstrated.

Due to their affinities, PS and PAH may be grouped under the label of hypersomnia with periodic breathing (HPB) (Coccagna, Mantovani, Ceroni, Pazzaglia, Petrella, and Lugaresi, 1970).

In HPB the following basic observations have been made:

(1) The periodic breathing with recurring apnoea, lasting from 20 to 80 seconds with intercurrent profound respiration, appears at each dozing off and persists through sleep (Jung and 
Kuhlo, 1965; Gastaut, Tassinari, and Duron, 1965; Lugaresi, Coccagna, Petrella, Ceroni, and Pazzaglia, 1968b).

(2) The apnoea may be central (characterized by the interruption and simultaneous resumption of oral and thoracic breathing), obstructive (characterized by the persistence of the thoracic movements after the interruption of oral respiration), or mixed (characterized by the intial interruption and subsequent resumption of the thoracic movements during oral apnoea (Gastaut et al., 1965; Gastaut, Duron, Papy, Tassinari, and Waltregny, 1966).

(3) The obstructive phenomenon is secondary to the halting or weakening of central breathing; this is indicated by the variations in the endoesophageal pressure (Lugaresi et al., 1968b) and the EMG activity of the intercostal muscles (Kuhlo, 1968), which is less than normal in the initial period of the obstruction. In all likelihood the obstruction of the upper respiratory tract is due to a decrease in tone of the pharyngeal muscles which causes the obstruction of the pharynx by means of a valve-like mechanism (Gastaut et al., 1965; Coccagna, Petrella, Ceroni, Lugaresi, and Pazzaglia, 1968; Schwartz and Escande, 1968).

(4) Daytime drowsiness is not due to carbonarcosis as several authors have hypothesized (Auchincloss and Gilbert, 1959; Drachman and Gumnit, 1962): in fact, in both PS and in PAH the $\mathrm{PaCO}_{2}$ measured during waking may be normal (Gastaut et al., 1965; Lugaresi et al., 1968a).

The present report deals with two cases of severe hypersomnia with periodic breathing and without obesity. In both patients the apnoea which appeared during sleep was mainly of the obstructive type. Tracheotomy was therefore performed and permanent tracheal cannulae were inserted. Surgery was followed by complete remission of the symptoms. The obstruction of the upper respiratory tract during sleep may therefore be regarded as the primary factor in the pathogenesis of hypersomnia with periodic breathing.

\section{CASE 1}

S.C., a 65 year old woman, was admitted to the Neurological Clinic in April 1968. She had fallen from a chair at the age of 3 years and suffered a fracture of both maxillary condyles with an ensuing mandibular malformation. She had snored noisily during sleep since infancy. The present condition dates back to four years before admission when crises of irrepressible, short duration, drowsiness began to appear during normal waking hours. At first the fits of sleep occurred only after meals or when the patient was resting or carrying out monotonous chores; they became progressively more frequent and prolonged. Occasionally she would fall asleep while standing and awaken just in time to avoid falling. Breathing was irregular and noisy both during nocturnal and diurnal sleep.

OBJECTIVE EXAMINATION The patient was not obese $(155 \mathrm{~cm}$ tall, weight $65 \mathrm{~kg}$ ); her facial traits were $\vec{\circ}$ altered owing to the presence of a mandibular hypoplasia which gave her a 'bird's beak' profile. Neurological examination was negative. No abnormalities were found in the lungs and heart. Brachial arterial pressure was $165 / 90 \mathrm{mmHg}$. The patient fell asleep repeatedly during the interview and examination, and constant stimulation was necessary to keep hev awake.

LABORATORY EXAMINATIONS Urinalysis, azotaemią글 and glycaemia were within normal limits; red ceff count was $4,680,000 / \mathrm{c} . \mathrm{mm}$; leucocytes were 7,10 \& c.mm with standard formula. The haematocrit wa $44 \%$.

Chest radiographs failed to show any cardiopu位 monary alteration. Skull radiography showed the presence of a mandibular hypoplasia with partial ankylosis of the temporomandibular articulation. An electrocardiogram (ECG) was normal.

RESPIRATORY FUNCTION TESTS Spirographic values $\overline{\bar{\sigma}}$ were obtained by means of a Pulmorex Godart closed circuit apparatus with the patient sitting and awake. Residual volume and flow resistance of the upper air passages were recorded with a Pulmorex volumetric plethysmograph.

All values, including average bronchial resistances, were within normal limits $\left(1 \cdot 7 \mathrm{~cm} \mathrm{H}_{2} \mathrm{O} / 1 . / \mathrm{sec}\right)$. Basic dynamic compliance with the patient awake $\delta$ was normal $\left(0 \cdot 18 \mathrm{l}\right.$./ $\left.\mathrm{cm} \mathrm{H}_{2} \mathrm{O}\right)$, but during light sleep with obstructive apnoea it diminished to $0.0551 . / \mathrm{cm}$ 응 $\mathrm{H}_{2} \mathrm{O}$.

Average $\mathrm{CO}_{2}$ alveolar pressure with the patient $\frac{D}{\mathrm{O}}$ awake was $41 \mathrm{mmHg}$; after brief voluntary hyperventilation it dropped to $35 \mathrm{mmHg}$; during the $\mathrm{N}$ falling asleep period it stabilized at about $48 \mathrm{mmHg}$. N In the course of sleep the oxygen saturation $\left(\mathrm{SaO}_{2}\right)$, N measured with an ear oximeter, fell rapidly to values 


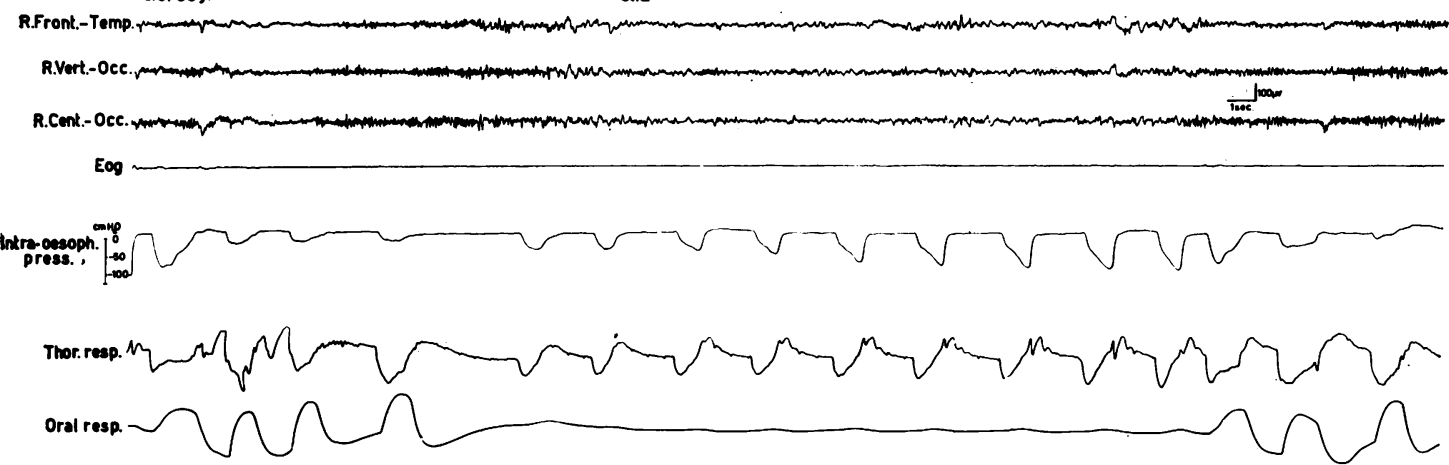

FIG. 1. Patient S.C. Episode of apnoea during stage 2 sleep. During the oral apnoea thoracic movements persist, progressively intensifying till the apnoea ends (obstructive apnoea). Resumption of breathing is preceded by EEG signs of arousal. (EEG: first three channels; horizontal electro-oculogram (EOG); endoesophageal pressure (Intraoesoph. press.); thoracic respiration (Thor. resp.); oral respiration (Oral resp.)).

below $70 \%$ during apnoea and returned to normal values when ventilation was resumed.

ARTERIAL GAS ANALYSIS Brachial arterial blood samples were taken using a Cournand needle; values were immediately measured using a radiometer apparatus (blood micro-system model BMS $3 \mathrm{~b}$; acid base analyser PHM 71 with $\mathrm{PO}_{2}$ module type PHA 930 and $\mathrm{PCO}_{2}$ module type PHA 931).

The gas analysis values of arterial blood with the patient awake were normal $\left(\mathrm{PaCO}_{2}: 38 \mathrm{~mm} \mathrm{Hg}\right.$; $\mathrm{PaO}_{2}: 90 \mathrm{~mm} \mathrm{Hg} ; \mathrm{pH} 7 \cdot 39 ; \mathrm{SaO}_{2}: 96.9 \%$ ). Gas analysis carried out during light sleep yielded the following values: $\mathrm{PaCO}_{2}: 49 \mathrm{~mm} \mathrm{Hg} ; \mathrm{PaO}_{2}: 56$ $\mathrm{mm} \mathrm{Hg} ; \mathrm{pH} 7 \cdot 32 ; \mathrm{SaO}_{2}: 86 \%$.

POLYGRAPHIC RECORDINGS The patient underwent a polygraphic recording lasting 24 hours. During the night she slept in a dark, quiet room, while during the daytime recording she sat in a comfortable armchair where she was able to read and eat. From time to time she was allowed to take a short walk. Recording was carried out by means of a model PF 14b Galileo polygraph; electroencephalogram (EEG) (3-4 channels), horizontal oculogram, electromyogram of the mylohyoid muscles with surface electrodes, oral spirogram obtained through a thermocouple placed in front of the mouth, and a thorax pneumogram were recorded simultaneously. Sleep stages were classified in accordance with the criteria suggested by Dement and Kleitman (1957).

During diurnal recording the patient underwent numerous episodes of sleep lasting from a few minutes to over half an hour. The nocturnal sleep was interrupted by numerous short reawakenings. Total time of diurnal and nocturnal sleep was $10 \mathrm{hr} 8 \mathrm{~min}$ in $15 \mathrm{hr} 20 \mathrm{~min}$ of effective recording. Of total sleep time she spent $33.8 \%$ in stage $1 ; 41.9 \%$ in stage 2 ; $7.3 \%$ in stages $3-4$; and $16.7 \%$ in the rapid eye movement (REM) stage.

During a subsequent nocturnal recording the endoesophageal pressure was also recorded, its modifications corresponding to variations in endothoracic pressure during respiration. A probe equipped with a small terminal balloon was introduced through the nose into the inferior third of the oesophagus. The probe was connected to a P23 Db Statham transducer, connected in turn to a manometric preamplifier of the polygraph (model Kemt-Eb).

Periodic breathing began with the onset of sleep and continued through both diurnal and nocturnal sleep. The simultaneous recording of the oral spirogram, the thoracic pneumogram and the endoesophageal pressure made it possible to establish that the apnoea was predominantly obstructive or mixed; even during ventilation the upper airways were sub-obstructed, as evidenced by the continued elevation of the negative endoesophageal pressure (Fig. 1); and only in the course of light sleep was central apnoea present. The duration of the central apnoea ranged from 10 to 20 seconds; the obstructive or mixed apnoea lasted from 60 to 90 seconds. The most protracted apnoea were recorded during REM sleep.

The patient was discharged and d-N-methylamphetamine (15 $\mathrm{mg}$ per diem) and respiratory analeptics were prescribed. She was readmitted in August 1969 because the diurnal hypersomnia had become more severe in spite of her having spontaneously increased the dosage of amphetamine (to 


\section{S.C. $66 y$.}


EKG
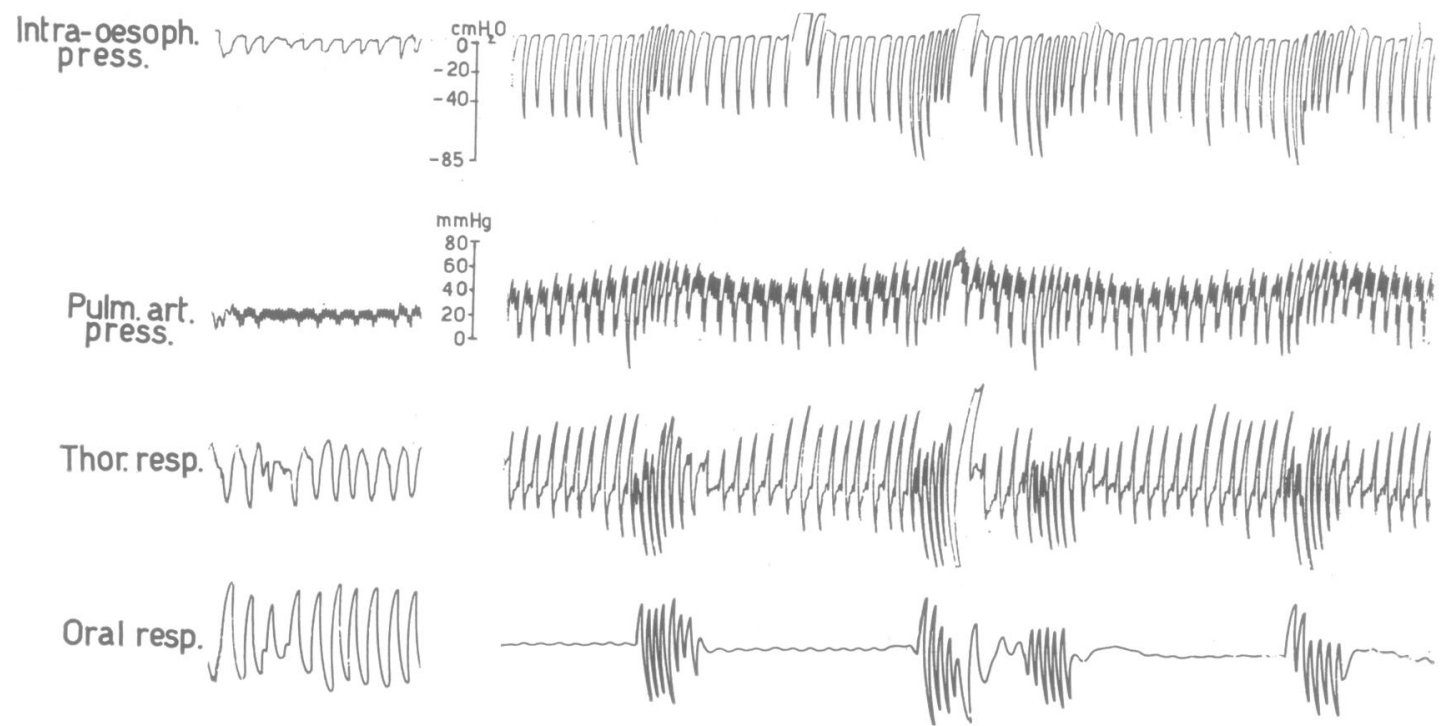

FIG. 2. Patient S.C. Recordings of respiration and pulmonary-arterial pressure during wakefulness $(W)$ and during sleep (St. REM). During wakefulness breathing is regular and pulmonary arterial pressure is normal. During sleep obstructive apnoea is present (persistance of thoracic movements during oral apnoea); endoesophageal pressure remains high even during resumption of pulmonary ventilation. Pulmonary arterial pressure (Pulm. art. press.) is noticeably increased and reaches maximum values at the end of each apnoea; during the apnoea the pressure shows marked oscillations corresponding with variations in intrathoracic pressure.

$60 \mathrm{mg}$ per diem). She stated that her normal condition was continuous sleep interrupted by short periods of waking. She arrived at the Clinic a day late because she had slept continuously during her train journey and only awakened some $200 \mathrm{~km}$ beyond the station at which she should have got off the train. The objective examination, the laboratory tests, and the tests of respiratory function yielded values similar to those observed during her previous stay at the Clinic.

POLYGRAPHIC RECORDINGS A new polygraphic re- cording over a 24 hour period demonstrated that the hypersomnia had indeed become more severe: out of 19 hours of actual recording the patient slept 17 hours (stage $1=16 \cdot 3 \%$; stage $2=48.3 \%$; stage $3-4=$ $14.6 \%$; REM stage $=20 \%$ ). Respiratory anomalies were unchanged. A nocturnal polygraphic recording was subsequently made during which the pressure of the pulmonary artery was recorded continuously by means of a Grandjean microcatheter (Grandjean, 1967). The microcatheter was connected to a $P 23 \mathrm{Db}$ Statham transducer connected in turn to an electromanometer of the polygraph (model Kemt-Eb). 



R.Cent-Occ.

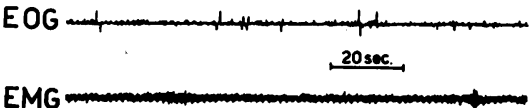

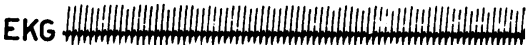

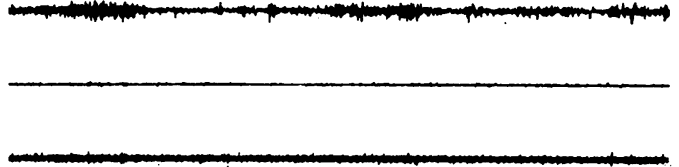

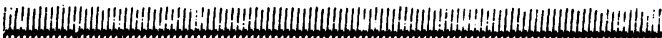

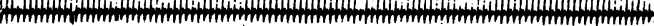
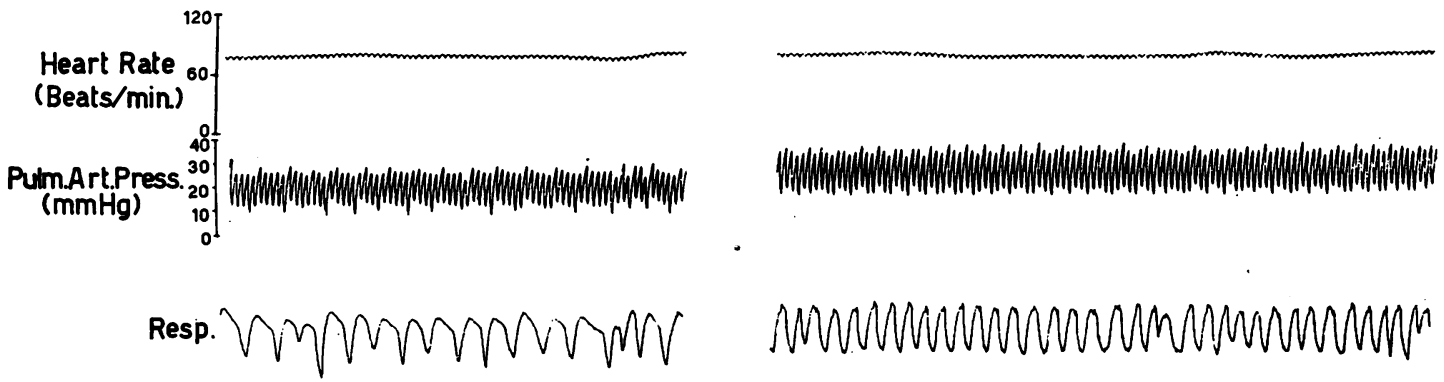

FIG. 3. Patient S.C. Recordings of respiration and pulmonary arterial pressure during wakefulness and sleep (Stage 2) after tracheotomy. During sleep breathing is regular and pulmonary arterial pressure is only slightly above normal values. (EMG =electromyogram of mylohyoid muscle).

In the period of wakefulness the pressure of the pulmonary artery showed values near the upper normal limit (27-30/12-16 mm $\mathrm{Hg})$; during sleep and with the appearance of periodic respiration it increased rapidly $(40-80 / 20-40 \mathrm{~mm} \mathrm{Hg})$ with highest values being reached in the REM stages. During obstructive apnoea pulmonary arterial pressure showed broad oscillation in relation to the variations in intrathoracic pressure (Fig. 2).

Since the apnoea was of a dominantly obstructive character, the patient was advised to undergo tracheostomy, but she refused. Two months after she had been discharged from our Clinic she was admitted to a hospital in her home town as an emergency case because her relatives had been greatly upset one night by her cyanotic state, her respiratory difficulties, and the fact that she remained awake for only a few minutes at a time in spite of their repeated attempts to keep her awake.

Following our advice the surgeons performed a tracheotomy and inserted a permanent cannula in her trachea. After a few days the patient was transferred to our Clinic where she underwent numerous diurnal and nocturnal polygraphic records. No episodes of daytime sleep were recorded and nocturnal sleep patterns rapidly normalized. Central apnoea, although initially still quite frequent, was reduced to sporadic incidence after 26 days. Waking pulmonary arterial pressure was normal (18-26/9-13 $\mathrm{mm} \mathrm{Hg}$ ). However, during sleep it was still slightly elevated (25-40/13-22 mm Hg) (Fig. 3).

Two years after the tracheostomy the patient is well accustomed to the tracheal cannula. She leaves it open only at night, closing it during the day so that she can speak normally and carry out all regular daily activities without being interrupted by episodes of diurnal sleep.

\section{CASE 2}

B.M., a 10 year old boy, was seen in our Clinic for the first time in 1967.

Delivery was normal. At the age of 10 months he began to suffer from frequent episodes of bronchitis which lasted until he reached 2 years of age. At 3 years of age breathing irregularities and cyanosis appeared during sleep. A year later daytime episodes of sleep began, accompanied by the same breathing irregularities that characterized his abnormal nocturnal sleep. If his jaw was supported, nocturnal respiration improved. In the hope of correcting these abnormalities he underwent adenoidectomy and 
PATIENT B.M. GAS ANALYTIC VALUES TAKEN OVER PERIOD OF YEARS DURING WAKEFULNESS AND SLEEP; GAS ANALYTIC MINIMAL VALUES) AT THE MOMENT

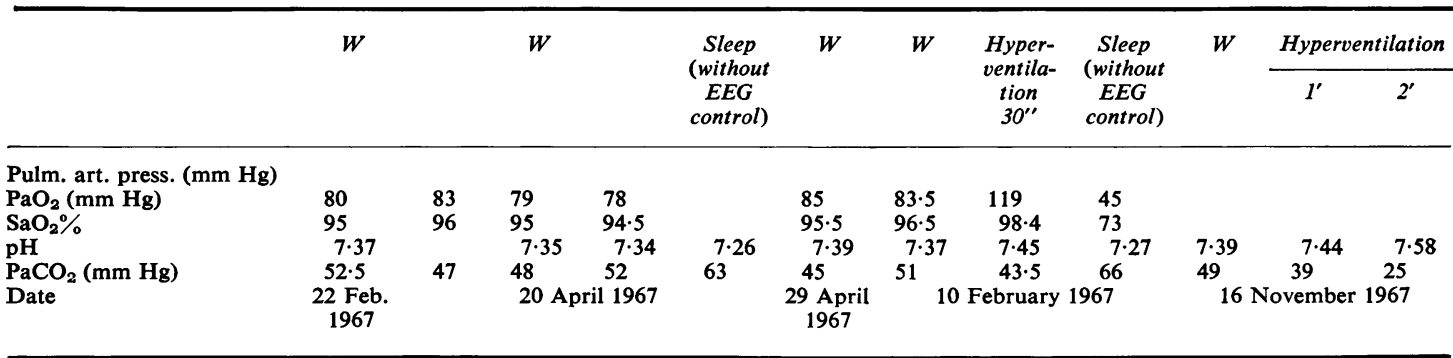

$\mathbf{W}=$ waking

tonsillectomy at 4 years of age, and again at 5 years. However, these operations failed to improve his condition, which rapidly and progressively worsened. In the two years preceding his hospitalization the patient managed to remain awake only when he was engaged in physical activity. As soon as he sat down and (or) attempted some mental activity such as reading or studying, he promptly fell asleep. During school hours his teacher was forced to call him to attention continuously in order to keep him awake and his scholastic performance was, naturally, minimal.

OBJECTIVE EXAMINATION The child was normally developed for his age; his height was $137 \mathrm{~cm}$ and he weighed $32 \mathrm{~kg}$. Examination of the respiratory system did not indicate any irregularities. Accentuation of the second heart sound was heard at the pulmonary area. The brachial arterial pressure was $110 / 70 \mathrm{~mm} \mathrm{Hg}$.

Neurological examination and examination of the fundus oculi both proved negative. The child cooperated with the examiner, even though repeated stimulation was necessary to keep him from falling asleep.

LABORATORY EXAMINATIONS Urinalysis, azotaemia, glycaemia, the blood Wassermann reaction, and the erythrocyte sedimentation rate were all within normal limits. The red cell count was 5,580,000/c.mm; haemoglobin $95 \%$; mean corpuscular volume $85 \mathrm{cu}$ microns; haematocrit $50 \%$; white blood cells $8,000 /$ c.mm with a normal leucocytic formula. Radiographs of the chest and cranium were both negative. The ECG showed prominent $P$ waves in leads $D_{2}$, $D_{3}$ and VF; $R$ wave in $V_{1}=8 \mathrm{~mm}$; deep negative $T$ waves in $V_{1}$ and $V_{2}$. This was interpreted as indicating right atrial involvement and right ventricular hypertrophy with systolic overload.
RESPIRATORY FUNCTION TESTS Spirographic values Both residual volume and the resistance of the upper $\vec{\omega}$ respiratory tract were found to be normal. Arterial gas analysis Partial pressure and saturation of $\frac{7}{0}$ oxygen $\left(\mathrm{PaO}_{2}\right.$ and $\left.\mathrm{SaO}_{2}\right)$, the $\mathrm{pH}$ and the partial $\omega$ pressure of carbon dioxide $\left(\mathrm{PaCO}_{2}\right)$ in the arterial blood when the patient was awake, during sleep, and also after voluntary hyperventilation were measuregl (see the preceding case for procedural details). TRe values obtained are summarized in the Table aloig $\overrightarrow{ }$ with the results obtained in successive determin $\mathbb{R}$ tions.

When the patient was awake the $\mathrm{PaO}_{2}$ and the $\mathrm{SaO}_{2}$ were within normal limits. However, the $\mathrm{PaCO}_{2}$ and the $\mathrm{pH}$ indicate the presence of a totalif or partially compensated respiratory acidosis. Volun- $\omega$ tary hyperventilation was followed by an elevated respiratory alkalosis. The values determined while the patient was asleep revealed a serious decrease in arterial oxygen saturation and a marked hypercapnic respiratory acidosis.

Breathing a mixture of $4 \%$ or $6 \% \mathrm{CO}_{2}$ in air for $\vec{F}$ 15 to 20 minutes caused an increase of ventilatory 3 volume per minute of about $500 \mathrm{ml}$. for each millimetre rise in the $\mathrm{PaCO}_{2}$ of the arterial blood, thus indicating decreased sensitivity of the respiratory centre to $\mathrm{CO}_{2}{ }^{2}$

POLYGRAPHIC RECORDINGS Over a period of a few months the patient underwent three 24 hour poly- $-\dot{\delta}$ graphic recordings and two nocturnal polygraphic recordings; during one of the latter the endoeso- 0 phageal pressure was also recorded (see the preceding case for procedural details). In each of the three 24 음 hour recordings the total time the patient was asleep exceeded 10 hours: on an average, the patient slept $\widetilde{N}$

2 In normal subjects the ventilatory response is approximately 1,000 $\mathrm{N}$ $\mathrm{ml}$. for each millimetre rise in $\mathrm{PaCO}_{2}$ (Alexander, West, Wood, and $\mathrm{\omega}$ Richards, 1955). 
VALUES FROM NOCTURNAL POLYGRAPHIC RECORDING DURING WHICH PULMONARY ARTERIAL PRESSURE (MAXIMAL AND OF SAMPLING IS INDICATED

\begin{tabular}{|c|c|c|c|c|c|c|c|c|c|c|c|c|c|}
\hline \multirow[t]{2}{*}{$\boldsymbol{W}$} & \multicolumn{12}{|c|}{ Sleep (polygraphic recording) } & \multirow{2}{*}{$\begin{array}{c}\text { Hyper } \\
\text { ventila } \\
\text { tion } \\
5^{\prime}\end{array}$} \\
\hline & $W$ & St. 3-4 & St. 2 & St. 3-4 & St. REM & St. REM & $\boldsymbol{W}$ & St. REM & St. 3-4 & St. REM & St. 3-4 & $\boldsymbol{W}$ & \\
\hline $\begin{array}{c}90 \\
96 \cdot 5 \\
7 \cdot 35 \\
49 \cdot 5 \\
27 \text { March } \\
1970\end{array}$ & $\begin{array}{l}30 / 8 \\
87 \\
96 \cdot 6 \\
7 \cdot 41 \\
43\end{array}$ & $\begin{array}{l}86 / 50 \\
45 \\
74 \\
7 \cdot 29 \\
56\end{array}$ & $\begin{array}{l}84 / 56 \\
46 \\
78 \\
7 \cdot 33 \\
61 \cdot 5\end{array}$ & $\begin{array}{l}88 / 52 \\
49 \\
80 \cdot 5 \\
7 \cdot 32 \\
54\end{array}$ & $\begin{array}{l}120 / 80 \\
61 \\
89 \\
7 \cdot 31 \\
54 \\
3 \text { April } 1\end{array}$ & $\begin{array}{c}120 / 80 \\
35 \\
57 \\
7 \cdot 26 \\
62 \\
971\end{array}$ & $\begin{array}{l}28 / 8 \\
86 \\
95 \cdot 7 \\
7 \cdot 32 \\
50\end{array}$ & $\begin{array}{c}128 / 68 \\
39 \\
66 \\
7 \cdot 29 \\
61\end{array}$ & $\begin{array}{l}88 / 52 \\
49 \\
79 \\
7 \cdot 29 \\
56\end{array}$ & $\begin{array}{l}100 / 64 \\
44 \\
71 \\
7 \cdot 26 \\
62\end{array}$ & $\begin{array}{l}92 / 52 \\
45 \\
75 \\
7 \cdot 31 \\
58\end{array}$ & $\begin{array}{l}32 / 8 \\
88\end{array}$ & $\begin{array}{c}28 / 4 \\
75 \\
94 \cdot 9 \\
7 \cdot 39 \\
44\end{array}$ \\
\hline
\end{tabular}
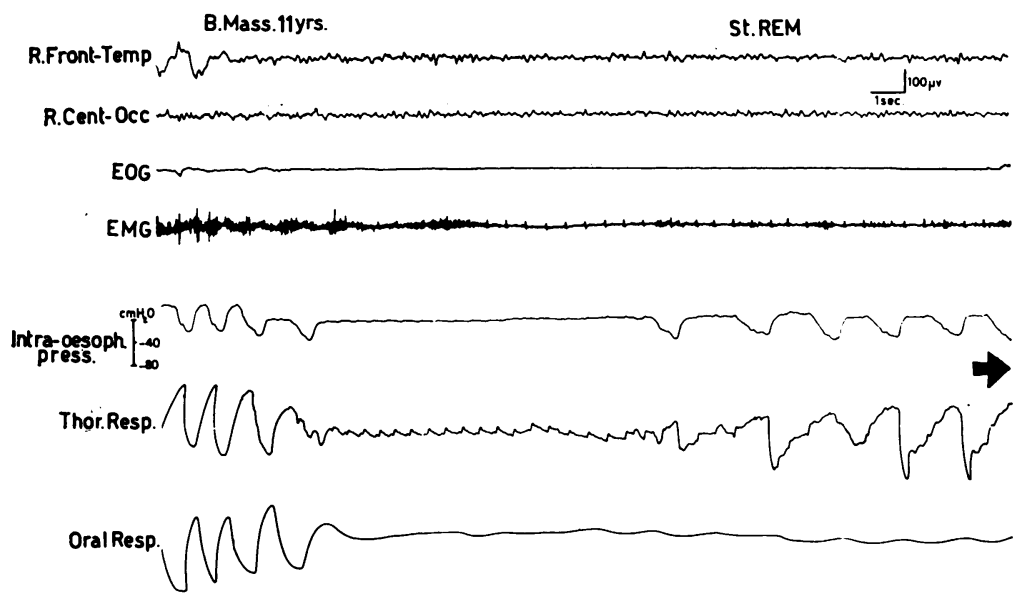

FIG. 4 Patient B.M. Episode of apnoea during REM sleep. The onset of the apnoea is characterized by arrested oral and thoracic respiration. With resumption of thoracic movements, oscillations appear in the endoesophageal pressure which intensify until pulmonary ventilation resumes (mixed apnoea).

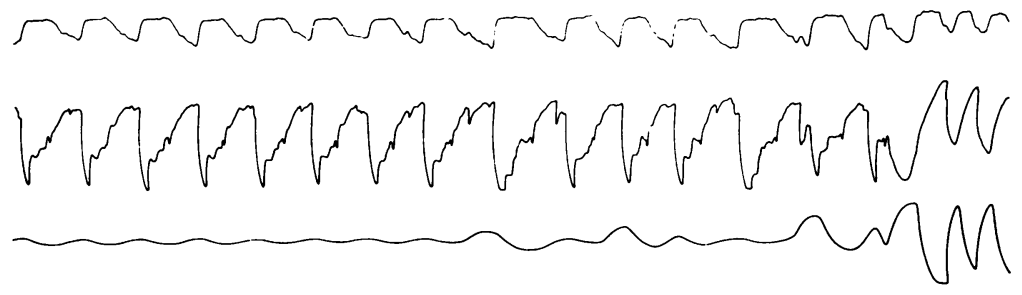


11 hours and 45 minutes of the 16 hours and 20 minutes of effective recording. Of total sleep time, he spent: $24.5 \%$ in stage $1 ; 38.5 \%$ in stage $2 ; 23 \%$ in stages $3-4$; and $14 \%$ in REM stage. Periodic apnoea appeared while the patient was falling asleep and persisted for the duration of sleep. The apnoea was predominantly of a mixed kind-that is, the appearance of the obstructive component was almost always preceded by a central respiratory arrest (Fig. 4). The duration of the apnoea that was purely central in nature varied from 10-20 seconds; the mixed or obstructive apnoea lasted from 70-95 seconds. The more prolonged apnoea appeared during REM sleep.

The patient was discharged and respiratory stimulants and $\mathrm{d}-\mathrm{N}$-methamphetamine $(10 \mathrm{mg} /$ day $)$ were prescribed. Daytime drowsiness improved but the respiratory disturbances that appeared during nocturnal sleep were not modified.

Because of increasing drowsiness and worsening respiratory disturbances the patient was readmitted to our clinic in March 1970. New tests of respiratory function, blood gas values, an ECG, and other laboratory examinations provided data that exactly coincided with the results obtained from testing during the patient's first stay.

POLYGRAPHIC RECORDING The patient underwent a nocturnal polygraphic recording during which pulmonary arterial pressure was recorded simultaneously with oral and thoracic respiration and endoesophageal pressure (see preceding case for procedural details).

The pulmonary arterial pressure, which was normal while the patient was awake $(22-28 / 4-8 \mathrm{~mm} \mathrm{Hg})$, rapidly and progressively increased with the deepening of sleep beginning with the initial period of drowsing off and continuing to the phase of deep 응 'slow' sleep (36-60/21-44 mm Hg). During REM क sleep the pulmonary arterial pressure demonstrated $\overrightarrow{0}$ a further and conspicuous increase in values of 90/70 $\mathrm{mm} \mathrm{Hg}$. We also recorded wide pressure oscillations $\vec{\omega}$ during the obstructive phases of the apnoea which coincided with similar changes in the endoesophageal pressure.

The results of the polygraphic recordings suggested
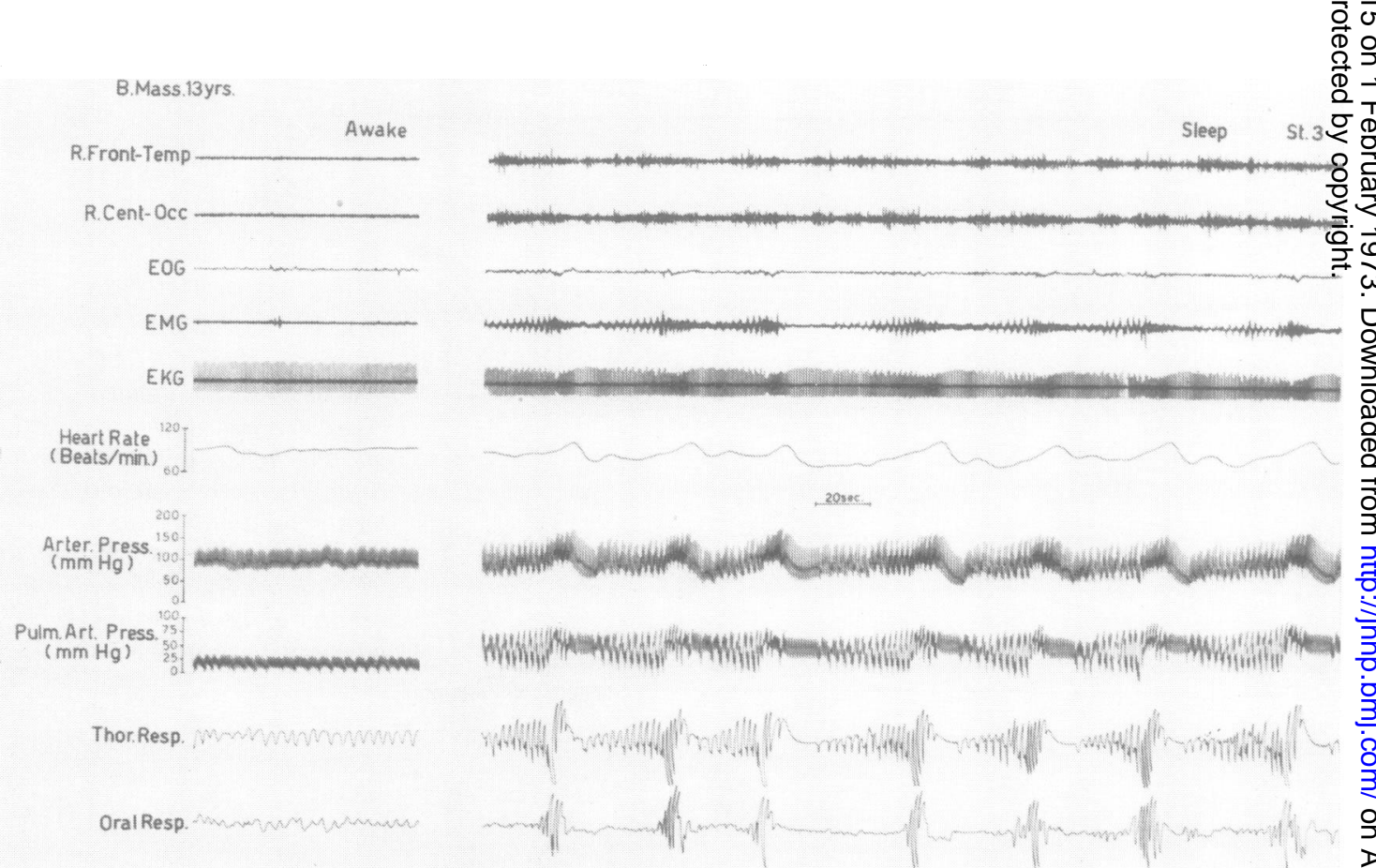

FIG. 5. Patient B.M. Recording of respiration and pulmonary arterial pressure during wakefulness and sleep (stage 3). During wakefulness breathing is regular and pulmonary arterial pressure is normal. Apnoea appears during sleep and is prevalently mixed. Pulmonary arterial pressure is high and reaches maximum values at the end of each period of apnoea when tachycardia appears and systemic arterial pressure rises (Arter. Press.). 
trying tracheostomy as a therapeutic possibility. However, the parents of the patient refused to give permission for the operation and he was subsequently discharged. By February 1971 the condition of the patient had further deteriorated, even though he had increased his dosage of amphetamine. He slept almost continually while at school and the protracted respiratory arrests and intense cyanosis that appeared while he was asleep alarmed his teachers and schoolmates.

After his readmission, in March 1971, we made a new polygraphic recording incorporating simultaneous registration of pulmonary and systemic arterial pressure. Systemic arterial pressure was obtained by means of a Teflon Longdwell needle surgically placed in the radial artery and connected to a Statham P23 Db transducer by a Teflon tube. The transducer was in turn connected to an electromanometer of the polyphysiograph (model KemtEb). During the recording numerous samples of arterial blood were taken for gas analysis, which was immediately performed. Pressure in the pulmonary artery when the patient was awake was slightly higher than normal $(35-40 / 9-12 \mathrm{~mm} \mathrm{Hg}$; average: $23 \mathrm{~mm} \mathrm{Hg}$ ), and reached extremely high levels during sleep ('slow' sleep: $60-80 / 30-60 \mathrm{~mm} \mathrm{Hg}$; average: 40-60 mm Hg; REM sleep: 90-130/60-80 mm Hg; average: $75-90 \mathrm{~mm} \mathrm{Hg}$ ) (Fig. 5). Results of blood gas analysis were only slightly abnormal when the patient was awake but indicated a serious decrease in $\mathrm{SaO}_{2}$ and an intense hypercapnic respiratory acidosis during sleep (Table).

The tracheotomy was performed on 4 April 1971 and a tracheal cannula was permanently inserted. Nocturnal sleep and respiration normalized immediately after the operation and daytime drowsiness completely disappeared. An ECG demonstrated the disappearance of right atrioventricular overload and the persistence of right ventricular hypertrophy.

POST-OPERATIVE POLYGRAPHIC RECORDINGS Nine days after the operation the patient slept for nine of the 10 hours of nocturnal registration. The cyclic succession of the single stages of sleep was normal (stage $1=5 \cdot 6 \%$, stage $2=37 \cdot 1 \%$, stage $3-4=22 \cdot 7 \%$, and REM stage $=34.5 \%$ ). No further episodes of
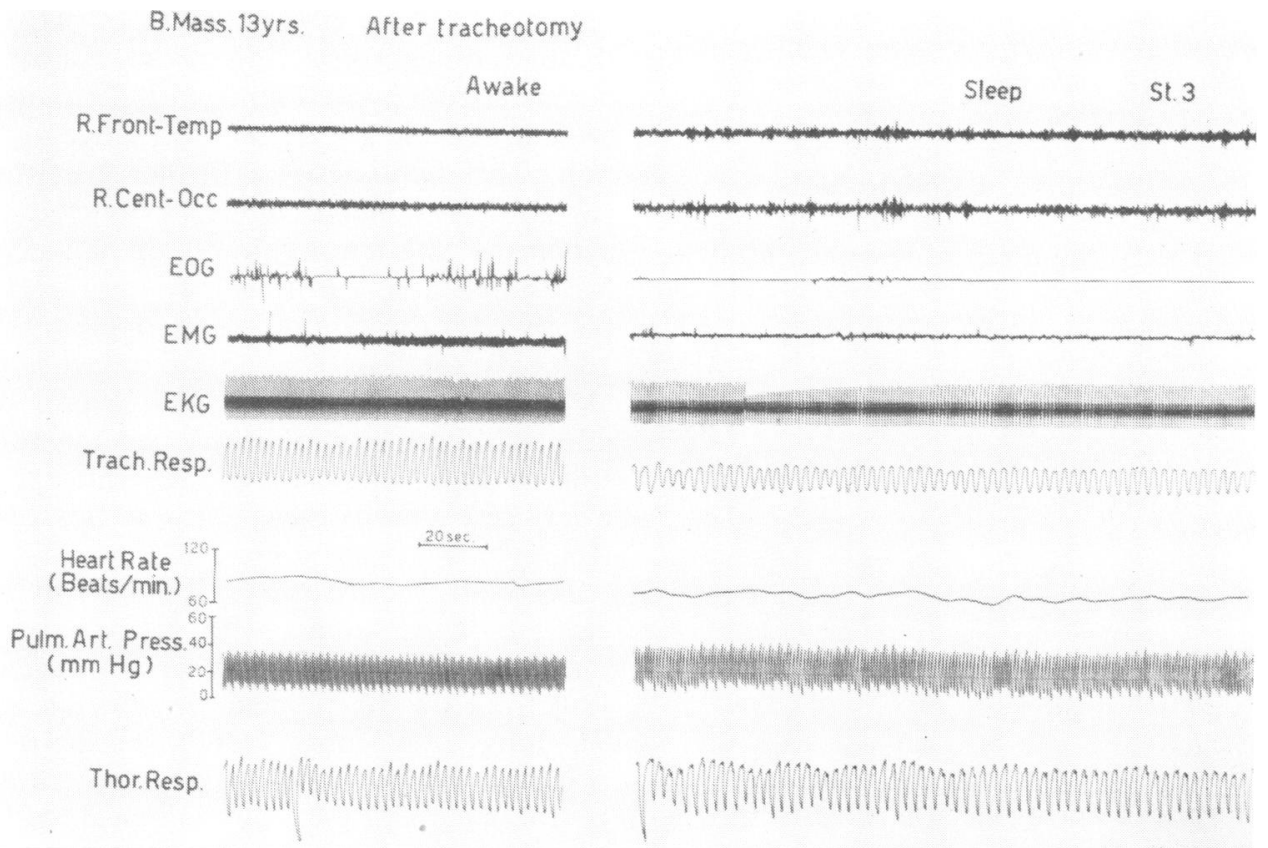

FIG. 6. Patient B.M. Recordings of respiration and pulmonary arterial pressure during wakefulness and sleep (Stage 3) after tracheotomy. Only minimal variations in depth of breathing occur during sleep. Pulmonary arterial pressure is slightly above normal values. (Trach. resp. = breathing recorded with a thermocouple placed in front of the tracheal stoma.) 


\section{Primary factors}

Initial clinical features

Final stage

Diminished sensitivity of Depression of the

$\rightarrow$ Diurnal alveolar

Peripheral mechanisms favouring obstruction of air passages (obesity, bulbar poliomyelitis, tonsillar and adenoidal hypertrophy, mandibular malformations, etc.) hypoventilation

Periodic breathing with obstruction of the upper air-ways during sleep Nocturnal hypoventilation $\left(+\mathrm{CO}_{2} ;-\mathrm{O}_{2}\right)$ Pulmonary $\longrightarrow$ Cor pulmonale hypertension Polycythaemia

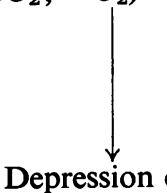

Depression of R.A.S. $\rightarrow$ Hypersomnia Obesity (?)

FIG. 7. Possible pathogenetic pattern in hypersomnia with periodic breathing.

apnoea were observed, although periodic oscillations in the depth of respiration that did not correspond to any stage of sleep were noted occasionally during the recording.

Thirty days after the tracheotomy another polygraphic recording incorporating measurements of the pulmonary arterial pressure was made. When the patient was awake, the pressure values were slightly lower than those encountered before the operation (28-32/4-10 $\mathrm{mmHg}$; average: $12-14 \mathrm{~mm}$ $\mathrm{Hg}$ ). During sleep the pressure remained at about the same level or tended to increase slightly (32-46/ 8-18 $\mathrm{mmHg}$; average: $16-26 \mathrm{mmHg}$ ) (Fig. 6). The highest pressure values occurred during stages $3-4$.

Ten months after the operation the patient is enjoying good health; for the first time in his life he is able to carry on a normal social existence. During the day he manages to speak perfectly by keeping the tracheal stoma closed. He only need open it at night. And finally, his scholastic performance has become completely normal.

\section{DISCUSSION}

In the present observations the removal of obstructive apnoea during sleep has led to the disappearance of diurnal drowsiness. An overall improvement has occurred with a decrease in the incidence of central apnoea and a normalization of gas analysis and pulmonary pressure values during sleep. Similar results have been observed by Kuhlo, Doll, and Franck (1969) in a case of $\overrightarrow{0} \cdot \overrightarrow{0}$ Pickwickian syndrome treated with trachem ostomy. In addition, these authors reported reduction of the obesity in their patient. Af these findings suggest that the abnormalities characterizing hypersomnia with periodic respiof ation are secondary to the obstructive phenome non. This hypothesis is further confirmed bo two observations in which a hypoventilatory syndrome with obesity, hypersomnia, stertorous breathing, and cardiomegaly regressed completely after excision of hypertrophic tonsils and adenoids to clear the upper respiratory tract (Menashe, Farrehi, and Miller, 1965). We can add a hitherto unpublished personal observation: a Pickwickian syndrome which regressed after correction of the tracheal stenosis residual to previous laryngectomy.

If the obstructive apnoea is indeed an essential cause of hypersomnia with periodic breathing, one can try to identify the series of events that 3 . lead from this phenomenon to the disease (Fig. 8 7). Jung and Kuhlo (1965) suggested that a primary hypoexcitability of the respiratory윽 centre, magnifying the physiological tendency to $>$ breathe periodically during sleep (Bülow and Ingvar, 1961), might account for the appearance $N$ of recurring apnoea. However, polygraphic in- $N$ vestigations have revealed that in all the hyper- $N$ somnia-hypoventilatory syndromes the majority 
of cases of central apnoea are complicated by obstruction of the upper air passages.

The decrease in central respiratory stimulation of the oropharyngeal muscles and the lack of tone coordination it produces could warrant the appearance of the obstructive phenomenon. There are, however, some instances in which a mechanical obstruction such as tonsillar and adenoidal hypertrophy or tracheal stenosis is certainly the primary cause of the abnormality. This was the case in our first patient who has had a mandibular malformation since early childhood: it is quite likely that this subocclusive peripheral factor has played a primary role.

The intervention of central factors (hypoexcitability of the respiratory centre and hypotonia of the oropharyngeal muscles during sleep) and of peripheral factors (obesity, bulbar poliomyelitis, tonsillar and adenoidal hypertrophy, mandibular malformations) contribute, perhaps to a different degree in each case, to the pathogenesis of the syndrome.

The obstruction of the upper air ways and the periodic breathing that occur during sleep favour a hypoxic-hypercapnic condition with resulting pulmonary hypertension. Retention of $\mathrm{CO}_{2}$, even if limited to the sleep hours, progressively reduces the excitability of the respiratory centre. This effect is documented not only in cases in which hypercapnia is persistent such as in emphysema, but also in instances of intermittent hypercapnia such as the conditions of underwater swimmers (Goff and Bartlett, 1957; Auchincloss and Gilbert, 1959).

In time, as the respiratory hypoexcitability becomes more pronounced, conditions are created which lead to a worsening of the syndrome; alveolar hypoventilation and $\mathrm{CO}_{2}$ retention extend to the waking hours, while the abnormalities that usually accompany conditions of chronic alveolar hypoventilation make their appearance - that is, polyglobulia, right ventricular hypertrophy, and right heart failure.

Diurnal drowsiness and obesity could be attributed respectively to the insomnia produced by recurring nocturnal apnoea (Gastaut et al., 1966) and to the diminished caloric consumption consequent on the lack of movement (Sieker et al., 1960).

It is possible, however, that the hypercapnia itself favours the appearance of hypersomnia and obesity by depressing the excitability of the $\mathrm{CO}_{2}$ sensitive structures involved in the regulation of wakefulness and of metabolism, such as, for instance, the reticular activating system (RAS) (Bonvallet, Hugelin, and Dell, 1955) and/ or the ergotropic portion of the hypothalamus (Gellhorn, 1953).

The question is if and when it is advisable to make a tracheostomy in patients suffering from HPR. Obviously, a definite answer cannot be given because the cases that have been studied so far are too limited in number and are too recent to allow us to draw any wide conclusions.

It seems to us, that tracheostomy should be considered in those cases in which weight loss has not been obtained and/or those in which there is no sub-obstruction of the upper air passages which can be treated surgically.

\section{REFERENCES}

Alexander, J. K., West, J. R., Wood, J. A., and Richards, D. W. (1955). Analysis of the respiratory response to carbon dioxide inhalation in varying clinical states of hypercapnia, anoxia, and acid-base derangement. Journal of Clinical Investigation, 34, 511-532.

Auchincloss, J. H., Jr., Cooke, E., and Renzetti, A. D. (1955). Clinical and physiological aspects of a case of obesity, polycythemia and alveolar hypoventilation. Journal of Clinical Investigation, 34, 1537-1545.

Auchincloss, J. H., Jr., and Gilbert, R. (1959). La sindrome cardiorespiratoria da obesità: quadro clinico e fisiopatologia. Progressi in Patologia Cardiovascolare, 2, 215-227.

Bonvallet, M., Hugelin, A., and Dell, P. (1955). Sensibilité comparée du système réticulé activateur ascendant et du centre respiratoire aux gaz du sang et à l'adrénaline. Journal de Physiologie (Paris), 47, 651-654.

Bülow, K., and Ingvar, D. H. (1961). Respiration and state of wakefulness in normals studied by spirography, capnography and EEG. A preliminary report. Acta Physiologica Scandinavica, 51, 230-238.

Burwell, C. S., Robin, E. D., Whaley, R. D., and Bickelmann, A. G. (1956). Extreme obesity associated with alveolar hypoventilation-a Pickwickian syndrome. American Journal of Medicine, 21, 811-818.

Carroll, D. (1956). A peculiar type of cardiopulmonary failure associated with obesity. American Journal of Medicine, 21, 819-824.

Coccagna, G., Petrella, A., Ceroni, G., Lugaresi, E., and Pazzaglia, P. (1968). Polygraphic contribution to hypersomnia and respiratory troubles in the Pickwickian syndrome. In The Abnormalities of Sleep in Man, pp. 215-221. Proceedings of the XVth European Meeting on EEG, Bologna 1967. Edited by H. Gastaut, E. Lugaresi, G. Ceroni, and G. Coccagna. Gaggi: Bologna.

Coccagna, G., Mantovani, M., Ceroni, G, Pazzaglia, P., Petrella, A., and Lugaresi, E. (1970). Sindromi ipersonniche-ipoventilatorie. Considerazioni sui rapporti fisiopatologici e nosografici tra sindrome pickwickiana, ipoventilazione alveolare primaria e narcolessia a sonno lento. Minerva Medica, 61, 1073-1084.

Dement, W., and Kleitman, N. (1957). Cyclic variations in EEG during sleep and their relation to eye movements, 
body motility, and dreaming. Electroencephalography and Clinical Neurophysiology, 9, 673-690.

Drachman, D. B., and Gumnit, R. J. (1962). Periodic alteration of consciousness in the 'Pickwickian' syndrome. Archives of Neurology, 6, 471-477.

Fishman, A. P., Goldring, R. M., and Turino, G. M. (1966). General alveolar hypoventilation: a syndrome of respiratory and cardiac failure in patients with normal lungs. Quarterly Journal of Medicine, N.S. 35, 261-275.

Gastaut, H., Tassinari, C. A., and Duron, B. (1965). Étude polygraphique des manifestations épisodiques (hypniques et respiratoires) diurnes et nocturnes, du syndrome de Pickwick. Revue Neurologique, 112, 568-579.

Gastaut, H., Duron, B., Papy, J.-J., Tassinari, C. A., and Waltregny, A. (1966). Etude polygraphique comparative du cycle nycthémérique chez les narcoleptiques, les Pickwickiens, les obèses et les insuffisants respiratoires. Revue Neurologique, 115, 456-462.

Gellhorn, E. (1953). On the physiological action of carbon dioxide on cortex and hypothalamus. Electroencephalography and Clinical Neurophysiology, 5, 401-413.

Goff, L. G., and Bartlett, R. G., Jr. (1957). Elevated end-tidal $\mathrm{CO}_{2}$ in trained underwater swimmers. Journal of Applied Physiology, 10, 203-206.

Grandjean, T. (1967). Une microtechnique du cathétérisme cardiaque droit praticable au lit du malade sans contrôle radioscopique. Cardiologia (Basel), 51, 184-192.

Jung, R., and Kuhlo, W. (1965). Neurophysiological studies of abnormal night sleep and the Pickwickian syndrome. In Sleep Mechanisms. Edited by K. Akert, C. Bally, J. P. Schadé. Progress in Brain Research, vol. 18, pp. 140-159. Elsevier: Amsterdam.

Kuhlo, W. (1968). Neurophysiologische und klinische Untersuchungen beim Pickwick-Syndrom. Archiv für Psychiatrie und Nervenkrankheiten, 211, 170-192.

Kuhlo, W., Doll, E., and Franck, M. C. (1969). Erfolgreiche Behandlung eines Pickwick-Syndroms durch eine Dauertrachealkanüle. Deutsche medizinische Wochenschrift, 94, 1286-1290.

Lillington, G. A., Anderson, M. W., and Brandenburg, R. O. (1957). The cardiorespiratory syndrome of obesity. Diseases of the Chest, 32, 1-20.
Lugaresi, E., Coccagna, G., Ceroni, G., Petrella, A., and $\underset{\Phi}{Z}$ Mantovani, M. (1968a). La 'Maledizione di Ondine': il disturbo del respiro e del sonno nell'ipoventilazione alveo-O are primaria. Sistema Nervosa, 20, 27-37.

Lugaresi, E., Coccagna, G., Petrella, A., Ceroni, G., and $\overline{\overline{0}}$ Pazzaglia, P. (1968b). Il disturbo del sonno e del respiro $\square$ nella sindrome pickwickiana. Sistema Nervosa, 20, 38-50.

Lugaresi, E., Coccagna, G., Mantovani, M., Brignani, F. $\frac{\rho}{\supset}$ (1970). Effets de la trachéotomie dans les hypersomnies avec respiration périodique. Revue Neurologique, 123, 267268.

Menashe, V. D., Farrehi, C., and Miller, M. (1965). Hypoventilation and cor pulmonale due to chronic upper airway obstruction. Journal of Pediatrics, 67, 198-203.

Naeye, R. L. (1961). Alveolar hypoventilation and cor pul-음 monale secondary to damage to the respiratory center. American Journal of Cardiology, 8, 416-419.

Rodman, T., and Close, H. P. (1959). The primary hypo- $\varrho$ ventilation syndrome. American Journal of Medicine, 26, 808-817.

Schwartz, B. A., and Escande, J. P. (1968). Respiration. $\vec{\circ}$ hypnique pickwickienne. In The Abnormalities of Sleep in $\overrightarrow{\vec{H}}$ Man, pp. 209-214. Proceedings of the XVth European Meeting on EEG, Bologna 1967. Edited by H. Gastaut, E. Lugaresi, G. Ceroni, and G. Coccagna. Gaggi: Bologna.

Seriff, N. S. (1965). Alveolar hypoventilation with normal lungs: the syndrome of primary or central alveolar hypo-? ventilation. Annals of the New York Academy of Science, 121, 691-705.

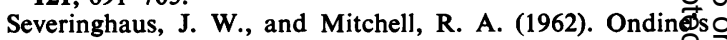
curse. Failure of respiratory center automaticity whife awake. (Abstract.) Clinical Research, 10, 122.

Sieker, H. O., Estes, E. H., Jr., Kelser, G. A., and McIntos H. D. (1955). A cardiopulmonary syndrome associatedd with extreme obesity. (Abstract.) Journal of Clinisal Investigation, 34, 916.

Sieker, H. O., Heyman, A., and Birchfield, R. I. (196). The effects of natural sleep and hypersomnolent states $\overline{0}$ respiratory function. Annals of Internal Medicine, 52, 500-. 516. 